Conclusion Although being considered potentially important, ACP did not occur often. HCPs seem to be reluctant to engage in ACP. The role of family in ACP is crucial in Asia. However, evidence was highly heterogeneous and limited to a few high-income countries, which limits its generalizability to other Asian countries.

\section{OP04 THE CONCEPT OF ACP: PERSPECTIVES OF PALLIATIVE CARE PATIENTS LIVING IN AN URBAN AREA IN MALAYSIA}

ZN Lim*. Hospis Malaysia, Kuala Lumpur, Malaysia

\subsection{6/spcare-2019-ACPICONGRESSABS.4}

Background What are the perspectives of palliative care patients living in an urban area in Malaysia on advance care planning ? Exploratory study to shape the concept of advance care planning according to local understanding and needs.

Methods This is a qualitative study, using semi-structured interviews with a purposive sampling of fifteen participants. All interviews were conducted in participants' homes. Interviews were audio-taped, transcribed verbatim and analysed. Thematic analysis was done through coding, theoretical sampling and finally integrating it into a conceptual framework.

Results All participants did not know what advance care planning was but was receptive to the idea of planning ahead. The main theme emerged from this exploratory qualitative study was individualised non-medical planning. This was shaped by factors such as participant's spirituality, prior health-related experiences, perceived psychosocial burden and information received on diagnosis, prognosis and availability of resources.

Conclusions The concept of advance care planning is foreign to palliative care patients living in Malaysia. Advance care planning is not seen as just purely medical-decision planning but it is seen as an interplay between psychosocial and relational factors. Palliative care patients in Malaysia vary considerably with regards to the extent to which they wish to engage in advance care planning discussion, but at the same time, may face barriers from healthcare professionals with poor communication skills. Awareness and education on advance care planning for both healthcare professionals and palliative care patients will eventually lead to improvement in end-of-life care planning.

\section{OP05 A CONVERSATION CARD GAME MOTIVATES BRITISH COLUMBIANS TO ENGAGE IN ADVANCE CARE PLANNING}

E Hassan*, D Barwich, K Kennedy. BC Centre for Palliative Care, New Westminister, Canada

\subsection{6/spcare-2019-ACPICONGRESSABS.5}

Background Advance care planning (ACP) is an important process that involves reflecting on, discussing and documenting one's values and preferences for future healthcare. A 2016 study in British Columbia (B.C.) showed that public engagement in ACP is low. The BC Centre for Palliative Care (BC-CPC) is leading a provincial initiative, in collaboration with various stakeholders, to promote early public engagement in ACP behaviours through innovative strategies. In 2016, BC-CPC partnered with 15 community-based organizations to assess the acceptability and effectiveness of a conversation card game in engaging the public in ACP conversations. Game questions are designed to stimulate conversations about issues relevant to decision making in the context of a serious illness.

Methods Participants were recruited by convenience sampling using community advertisements. During the game, participants take turns drawing cards, reading the questions on the cards aloud, and writing down their answers before sharing them with the group. Quantitative data was collected using a structured questionnaire to assess the participants' experience and motivation to engage in ACP.

Results Over 12 months, 547 British Columbian adults participated in 44 game events hosted by community organizations from across B.C. After playing the game, the majority of participants (90\%) planned to continue the conversation with family, and $75 \%$ agreed that the game made the conversations about the discussed topics safe and meaningful.

Conclusion Our findings indicate that playing the conversation game in a community setting is a feasible and effective way to motivate British Columbian to engage in ACP.

\section{OP06 PRIMARY CARE CLINICIANS' CONFIDENCE, WILLINGNESS AND PARTICIPATION IN ADVANCE CARE PLANNING DISCUSSIONS: A MULTI-SITE SURVEY}

${ }^{1} \mathrm{M}$ Howard*, ${ }^{1} \mathrm{C}$ Bernard, ${ }^{1} \mathrm{M}$ Slaven, ${ }^{1} \mathrm{~A}$ Tan, ${ }^{2} \mathrm{D}$ Barwich, ${ }^{3} \mathrm{D}$ Klein, ${ }^{1} \mathrm{D}$ Heyland. ${ }^{1}$ McMaster University, Hamilton, Canada; ${ }^{2} B C$ Centre for Palliative Care, Vancouver, Canada; ${ }^{3}$ University of Alberta, Edmonton, Canada

\subsection{6/spcare-2019-ACPICONGRESSABS.6}

Background People who engage in advance care planning (ACP) are more likely to receive healthcare that is concordant with their goals and wishes at the end of life. Primary care providers are ideally positioned to facilitate ACP. This study sought to describe the confidence, willingness and participation of primary care clinicians to have advance care planning discussions.

Methods We conducted a survey of family physicians and allied health professionals (AHP)in primary care in three Canadian provinces. We asked about willingness and confidence to have ACP discussions and current participation on Likert-type scales $(0=$ not at all, $6=$ an extreme amount). A modified Dillman approach was used for online survey administration.

Results The response rate was $72 \%(n=117)$ among physicians and $69 \%(n=62)$ among allied health professionals. Most physicians $(77 \%)$ were practicing in an interprofessional practice. The mean willingness to initiate ACP was 5.0 for physicians and 4.8 for AHP. Mean confidence ratings for initiating ACP was 4.8 for physicians and 3.5 for AHP. Current participation in ACP among patients aged 50 years and older was lower; 2.6 for physicians and 1.4 for AHP.

Conclusions The willingness of family physicians and AHP in primary care to initiate ACP discussions with patients is high. However, confidence is only moderate in AHP and actual activity is low for all clinicians. Efforts to remove barriers in primary care and provide support for AHP to improve their confidence to engage in ACP discussions should be priorities. 